\title{
Assembling of bearing sleeve on ship propulsion shaft by using EPY resin compound
}

\author{
Karol Grudziński, Prof. \\ Paweł Grudziński, Ph. D. \\ West Pomeranian University of Technology, Szczecin, POLAND \\ Wiesław Jaroszewicz, Ph. D. \\ Jędrzej Ratajczak, Ph. D. \\ Marine Service Jaroszewicz S.C., Szczecin, POLAND
}

\begin{abstract}
This paper presents an original novel solution of the problem of assembling a large bearing sleeve (of about $1000 \mathrm{~mm}$ in diameter) on ship propulsion shaft by using EPY resin compound. The problem is discussed on the concrete example dealing with a ship under repair. Design project of assembling the sleeve on the shaft by using the resin compound, model research on its casting process as well as assembling technology of the sleeve on the shaft, are presented and a practical way of realization of the project in conditions of a Chinese ship repair yard, is also highlighted. During more than three-year-long operation the solution has standed the test of time without any complaint.
\end{abstract}

Keywords: Bearing sleeve, propulsion shaft, assembling, EPY resin compound

\section{INTRODUCTION}

In the paper an original solution of the problem of assembling a large bearing sleeve (of about $1000 \mathrm{~mm}$ in diameter) on ship propulsion shaft, by using EPY resin compound, is presented. The compound belongs to a group of special epoxide compounds has been applied for many years to foundation chocks for seating main propulsion engines and reduction gears as well as many other machines and auxiliary devices, and to assembling stern tubes and bearing sleeves of rudder stocks, mounted on sea-going ships. The group is consisted of the three basic compounds: Chockfast Orange (USA), Epocast 36 (Germany) and EPY (Poland). They are granted all the certificates necessary for their wide application to assembling both shipboard and land-based machines and devices. Descriptions of their features as well as many practical applications can be found in producers' pamphlets available in Internet, as well as in the books $[1,2]$. According to the state of knowledge of these authors neither the compounds in question nor any other ones have been applied to assembling large bearing sleeves on ship propulsion shafts.

Until now the bronze bearing sleeves have been usually assembled on propulsion shafts of sea-going ships by means of thermo compression bonding. The assembling consists in heating the sleeve, free shifting it onto the shaft and cooling down to ambient temperature. Such solution was also applied in the case of the shaft in question, shown in Fig. 1, during building the ship. On the shaft two bearing sleeves were assembled by using the thermo compression method. During the capital repair of the ship it was revealed that to replace one of them has been necessary. The new sleeve which had to be assembled on the left part of the shaft ended with the large flange (Fig. 1) was of much greater dimensions than that which was in a good state and had to be left on the shaft. The form and dimensions of the new sleeve are shown in Fig. 2. The propeller shaft bearing has the sleeve fitted with rubber pads and is water - lubricated.

The repair of the ship (the Arkhangelsk which usually operates in Arctic waters) has been performed by the Estonian firm (OÜ Wärtsilä BLRT) of Tallin, in the Chinese shipyard (Yiu Lian Dock Yard Ltd, Shenzhan), under supervision of the Russian Maritime Register of Shipping.

The shipyard in which the ship was repaired had no practical possibility to assemble such a large sleeve on the shaft by means of the traditional method based on thermo compression. In the situation it was decided to assemble the sleeve on the shaft by using a special polimer compound widely applied for assembling many ship machines and devices. The firm which has carried out the repair of the ship announced a tender for realization of the work. In Asia and Europe there are many specialty firms engaged in seating machines and devices with the use of compounds. However, only one of them, a Polish company from Szczecin, has undertaken to do the novel and risk task.

The scope of the work consisted of elaboration of a detailed design project of assembling the sleeve on the shaft, technology of the assembling and its realization in the Chinese shipyard which carried out the repair of the ship in question. 


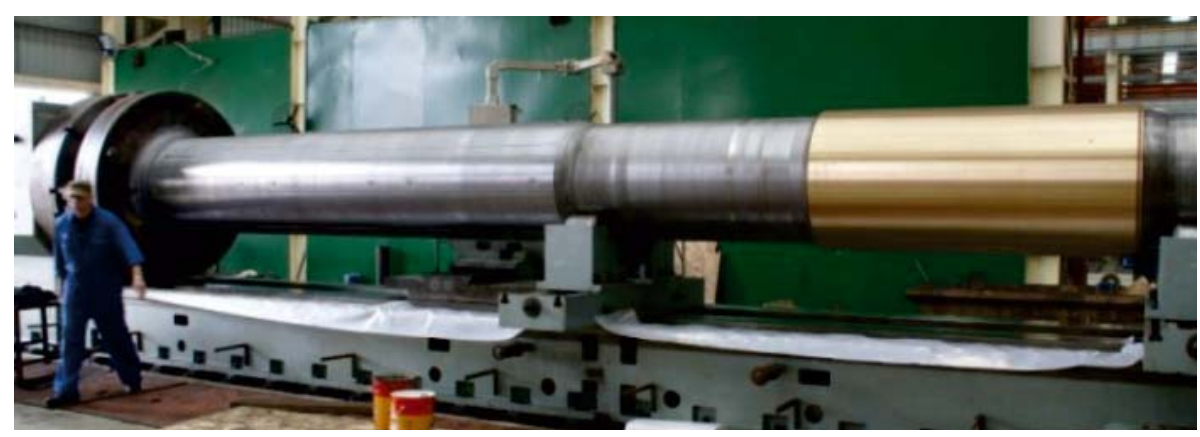

Fig. 1. The part of ship propulsion shaft, prepared for assembling the new bearing sleeve on it

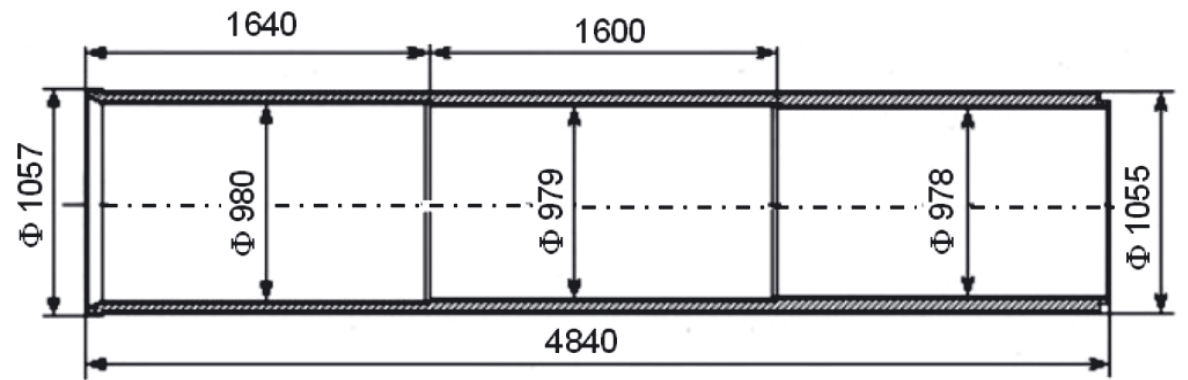

Fig. 2. The form and dimensions of the new bearing sleeve intended to be assembled on the shaft by using EPY compound

\section{DESIGN PROJECT OF ASSEMBLING THE SLEEVE ON THE SHAFT}

The design project of assembling the bearing sleeve on the ship propulsion shaft by using the EPY resin compound is shown in Fig. 3. The shaft is hollow and its outer diameter in the place of sleeve's assembling is a little differentiated alongside and has the values of 968,967 and $966 \mathrm{~mm}$ over the shaft sections of 1640,1600 and $1600 \mathrm{~mm}$ in length, respectively. Inside diameters of the sleeve are differentiated similarly (Fig. 2); they have respective values of 980,979 and $978 \mathrm{~mm}$. The difference of shaft and sleeve diameters over particular sections is constant and equal to $12 \mathrm{~mm}$. It gives the compound pouring gap of $6 \mathrm{~mm}$ in height over the whole length of the connection. This is a relatively small height of pouring gap (as compared with the large remaining dimensions) that is associated with many problems which have not been recognized so far. They deal with suitable filling the pouring space and getting a good casting of a small thickness and very large remaining dimensions. As results from the practical experience has been gained so far to obtain a good effect is difficult and associated with rather great risk in such a case. Worth mentioning that in the case of assembling stern tube in ship hull hub, of comparable or even much smaller dimensions, the applied height of pouring gap usually amounts to $15 \div 20 \mathrm{~mm}$, that is an important, but not the only, difference as compared with the solution applied in the project in question.

The full length of the bearing sleeve (Fig. 2) amounts to $4840 \mathrm{~mm}$, and its outer diameter is constant and equal to $1055 \mathrm{~mm}$. As internal diameters of the sleeve are somewhat different its wall thickness changes stepwise and has only a little differentiated values: $37.5,38.0$ and $38.5 \mathrm{~mm}$.

Because of manufacturing and assembling difficulties, three separate sleeves were prepared instead one, which - after shifting them onto the shaft - were next appropriately lap joined together (Fig. 3, D - detail), and they fulfilled their tasks, in this case, as properly as an integral sleeve. In order to ensure sleeve - shaft coaxiality as well as constant height of pouring gap 24 spacing elements of $6 \mathrm{~mm}$ in height were welded in suitable places of the shaft's surface (Fig. 3, B - detail). The elements welded on the shaft are seen also in Fig. 5.
On the upper generatrix of the bearing sleeve (before assembling) 5 openings (M30) for fixing ingate and flow-off pipes (Fig. 3, see C and D details), were drilled and threaded. Seals are provided in both ends of the sleeve (Fig. 3, see a and E details): internal one made of polyurethane foam (to stop resin compound outflow) and external permanent one to secure the joints against exposure to sea water. The special expoxide paste (Phillybond Orange Sealant Resin, ITW Philadelphia Resins) was used to form the seals. In the seals four venting openings were made (at the bottom, midheight and top), which were appropriately sealed after the liquid compound has been observed in them during pouring. The lap-joints of the particular parts of the sleeve were circumferentially sealed by using an adhesive tape. Also, in the top points of these seals control venting holes were provided, which were sealed during pouring process when the resin compound has been observed in them.

Cured resin compound which fills pouring space is intended to ensure not only integrity of the connection but also safe transmission of torque applied to bearing sleeve. It was assumed that circumferential forces acting on the connection have to be fully transferred by resin compound splines located in longitudinal splineways made on the internal surface of the sleeve and the external surface of the shaft. For this reason were designed 8 longitudinal splineways placed in the angular distance of $45^{\circ}$ to each other. Their form and dimensions are shown in Fig. 3, F and G details. After complete filling by the poured resin compound and its curing they form a correctly fitted multi-spline resin-compound connection between the shaft and bearing sleeve. The resin compound splines placed in splineways are exposed mainly to shear and surface compression. With a view of that appropriate control calculations were performed. The following input data were assumed:

- maximum propulsion shaft power

rotational speed of shaft

- radius of application of circumferential

force on contact surface between shaft

and resin compound

total length of spline (splineway)

spline breadth

spline (splineway) depth in shaft

$$
\begin{aligned}
& \mathrm{P}=15400 \mathrm{~kW} \\
& \mathrm{n}_{\mathrm{w}}=2 \mathrm{~s}^{-1}
\end{aligned}
$$

$\mathrm{R}=483 \mathrm{~mm}$

$\mathrm{L}=4840 \mathrm{~mm}$

$\mathrm{B}=10 \mathrm{~mm}$

$\mathrm{H}_{\mathrm{w}}=3 \mathrm{~mm}$ 

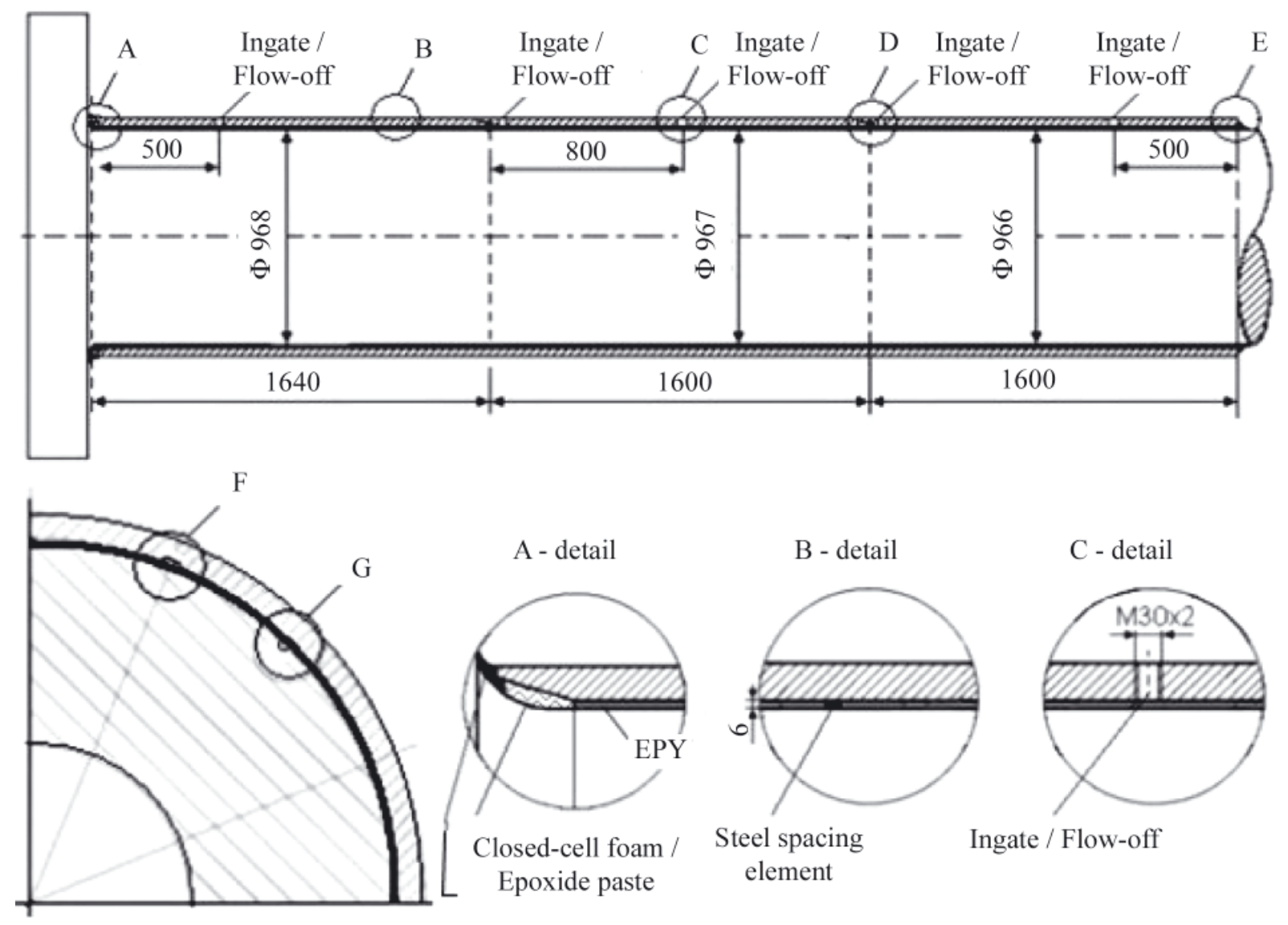

Steel spacing
element

Ingate / Flow-off

F - detail

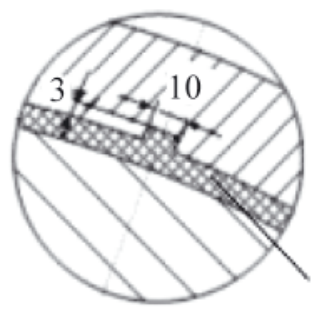

EPY
$\mathrm{G}$ - detail

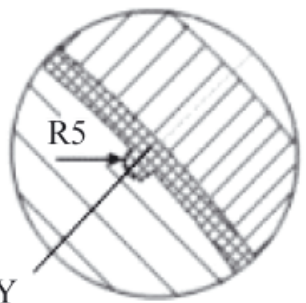

D - detail

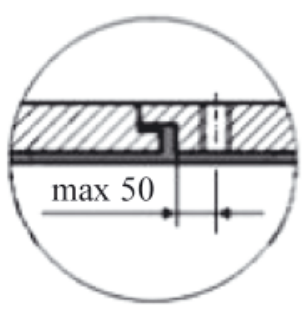

E - detail

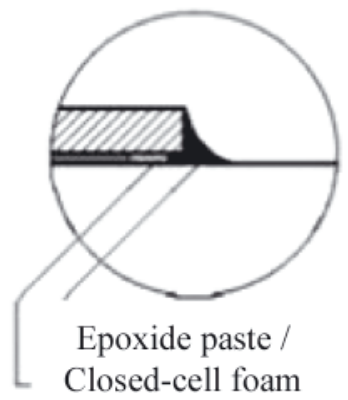

Fig. 3. Design project of assembling the bearing sleeve on the ship propulsion shaft by using the resin compound

- number of splines (splineways) over circumference

- resin compound shear strength

- resin compound compression strength

$$
\begin{aligned}
& \mathrm{n}_{\mathrm{r}}=8 \\
& \mathrm{R}_{\mathrm{t}}=59,1 \mathrm{MPa} \\
& \mathrm{R}_{\mathrm{c}}=169 \mathrm{MPa}
\end{aligned}
$$

Propulsion shaft torque:

$$
\mathrm{M}_{\mathrm{o}}=9550 \cdot 10^{3} \frac{\mathrm{P}}{\mathrm{n}_{\mathrm{w}}}=1225583 \mathrm{Nm}
$$

Total circumferential force on contact surface between shaft and resin compound:

$$
\begin{gathered}
\mathrm{F}_{\mathrm{T}}=\frac{\mathrm{M}_{\mathrm{o}}}{\mathrm{R}}=2537438 \mathrm{~N} \\
\text { Shear stresses: } \\
\tau=\frac{\mathrm{F}_{\mathrm{T}}}{\mathrm{n}_{\mathrm{r}} \mathrm{BL}_{\mathrm{T}}}=\frac{2537438}{8 \cdot 10 \cdot 4840}=6.55 \mathrm{MPa} \\
\mathrm{Surface} \text { compression: } \\
\mathrm{p}=\frac{\mathrm{F}_{\mathrm{T}}}{\mathrm{A}_{\mathrm{p}}}=\frac{2537438}{8 \cdot 3 \cdot 4840} \cdot=21.84 \mathrm{MPa}
\end{gathered}
$$

Shear safety factor:

$$
\mathrm{n}_{\tau}=\mathrm{R}_{\mathrm{t}} / \tau=8.95
$$

Compression safety factor:

$$
\mathrm{n}_{\mathrm{p}}=\mathrm{R}_{\mathrm{c}} / \mathrm{p}=7.74
$$

As results from the control calculations the values of shear and compression safety factors in conditions of extreme loading applied to the bearing sleeve by total shaft torque, are sufficiently large. Worth mentioning, that in the calculations extremely unfavourable conditions were assumed. As neither adhesion forces nor friction forces of resin compound on contact surfaces between shaft and sleeve were taken into account that really occurs and increases safety of such connection. In the calculations the maximum possible value of torque resulting from engine output was assumed to act onto the resin compound connection between shaft and sleeve. In usual service conditions of ship its shaft transmits torque from engine to screw propeller and only a small part of it is lost to overcome friction torque in bearings. In reality only this small part of torque is exerted to the made multi-spline resin-compound connection between shaft and bearing sleeve. As results from that, the real safety 

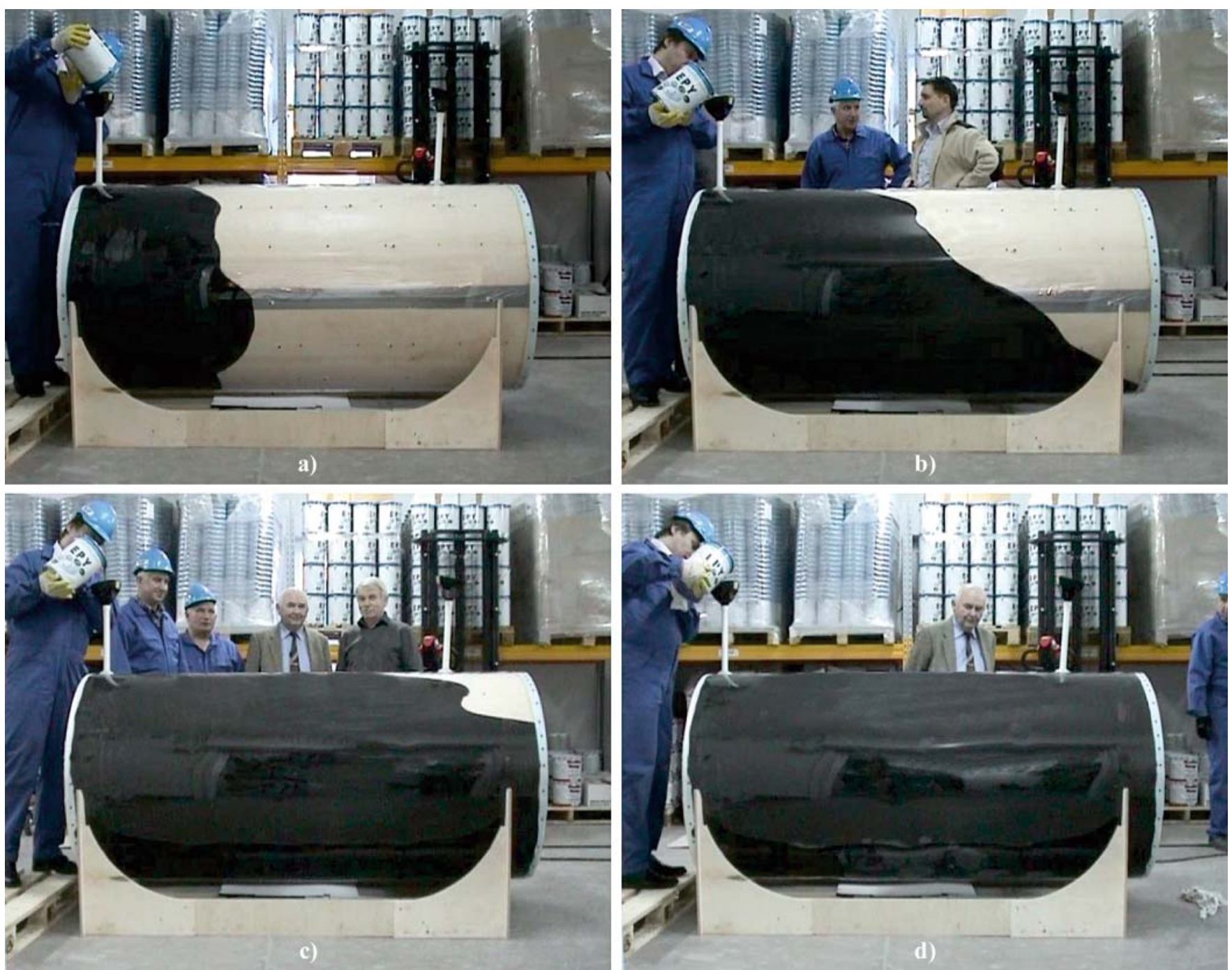

Fig. 4. Model tests of a manner and time of filling the pouring gap between shaft and sleeve with liquid EPY resin compound

factor values against shear and surface compression for the resin compound in regular ship operation conditions will be multifold greater than the above given ones calculated de facto for the situation of bearing failure when shaft rotation against bearing would be completely blocked. Such situations are completely unknown in practice.

Therefore it can be stated that from the strength point of view the designed connection between the sleeve and the shaft by using the EPY resin compound satisfies safety conditions with a very large margin.

\section{MODEL TESTS}

In spite of over thirty-year experience in seating ship machines and devices with the use of resin compound it was deemed necessary to conduct in advance appropriate model tests - because of definite specificity and great responsibility associated with the undertaking in question. The tests were aimed at practical checking if realization of the proposed solution is possible, and working out many details dealing with its manufacturing technology. The tested model of assembling the sleeve on the shaft with the use of EPY resin compound is shown in Fig. 4. Its diameter amounted to $1000 \mathrm{~mm}$, and its length to $2000 \mathrm{~mm}$. The gap height amounted to $4 \mathrm{~mm}$ that was ensured by appropriately arranged spacing elements. Conditions assumed for the model were less favourable than those for the real object. It concerned first of all the pouring gap height which was by $2 \mathrm{~mm}$ lower than that applied to the real system.
The shaft model was made of wood (model plywood wrapped around circular discs and stiffened appropriately by ribs) The outer sleeve was made of Plexiglas to make it possible to directly observe process of filling the pouring space with liquid resin compound. At the outer generatrix of the plexiglass sleeve two holes were made in which pipes ended with funnels, were fixed. They constituted ingate and flow-off for liquid resin compound, respectively. The distance between the ingate and flow-off holes to each other and from the sleeve ends were the same as in the real system. The $500 \mathrm{~mm}$ length of the pipes had to ensure an appropriate amount of the compound necessary for supplementing void cavities in the pouring space, until the instant of curing the compound. In the experiment it was important to practically test the pouring process performed through one hole, manner and rate of spreading the compound and possibility of correct filling the entire pouring space before starting gelation process. It was also important to determine real duration time necessary for realization of the operation in given temperature conditions

Sealing the pouring space at its edges was made with the use of polyurethane foam of open cells. It made additional venting the space during filling, possible. An important thing in the experiment was the testing of a manner of spreading the compound within the pouring space as well as quality of the formed casting after its curing in ambient conditions.

Results of the experiment have been very useful in working out many details of assembling technology of real sleeves onto ship propulsion shaft. In assembling technology of structural 

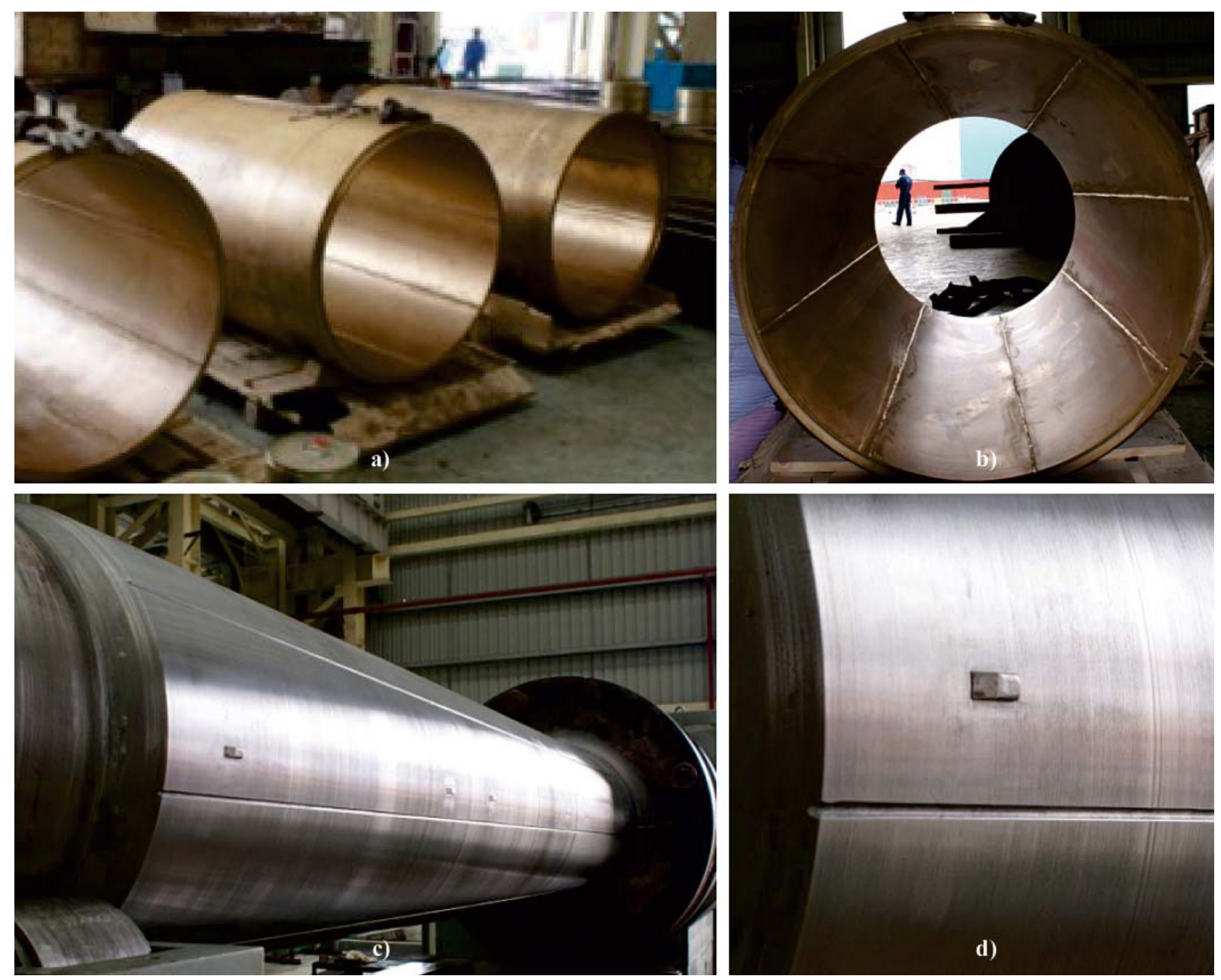

Fig. 5. Sections of the bearing sleeve and the shaft with cut splineways and welded spacing elements

elements with the use of resin compound there are many important details which may decide either on reaching success or suffering defeat in practical realization of such solutions.

\section{PREPARATION OF ELEMENTS AND RUN OF THEIR ASSEMBLING}

The sleeve sections to be assembled onto the shaft fragment, and the shaft itself, suitably prepared according to the design shown in Fig. 3, are presented in Fig. 5. Eight longitudinal splineways of the form and dimensions shown in Fig. 3 (F and $\mathrm{G}$ details) were cut both on the internal surface of the sleeve and the external surface of the shaft. On the shaft surface 24 spacing elements of $6 \mathrm{~mm}$ in height, were welded. They were aimed at ensuring a suitable arrangement of the sleeve against the shaft and a uniform pouring gap height. The spacing elements were appropriately beveled (Fig. 5d) to facilitate the process of shifting the sleeve onto the shaft and displacing it along the shaft. The inner surfaces of the sleeve were machined to the proper dimension by using a boring machine. The shaft surface was exactly cleaned by using sandpaper. Just before assembling the sleeve on the shaft their surfaces were exactly degreased by using acetone.

An overall view of the shaft and the first section of the bearing sleeve to be assembled (hanging on a girder crane) is shown in Fig. 6a. The sleeve is shifted onto the free (thinner) end of the shaft which is then placed on a roller support, at a distance from the end of the shaft (Fig. 6b). Next, after the appropriate fixing of the free end of the shaft and drawing aside the rollers of the support (Fig. 6b), the sleeve was shifted along the shaft axis up to the extreme location in the neighbourhood of the shaft's flange, by using the girder crane. In the same way were put onto the shaft and shifted along it two other sections of the bearing sleeve which were then lap-joined to each other. The assembling of the third section of the sleeve is shown in Fig. 6c.

The appropriate centering of the sleeve as well as pouring gap height were ensured by the spacing elements welded to the shaft (Fig. 5d). A minimum clearance which made shifting the sleeve possible was maintained. A small surplus of the outer diameter of the sleeve for its finishing after completing its assembling was provided.

After appropriate joining the particular sections of the sleeve to each other, the steel ingate and flow-off pipes with funnels welded to their upper ends, were screwed into them. The ends of the pouring space, and the sleeve joints were sealed in compliance with the above presented design project (Fig. 3). The sleeve-shaft system prepared for filling with the resin compound is shown in Fig. 7. The length of ingate and flow-off pipes equal to about $650 \mathrm{~mm}$, including funnels, was so chosen as to generate and maintain appropriate hydrostatic pressure necessary for correct filling the entire pouring space. Also, it is important to maintain some volume of resin compound within the flow-in and flow-off system after complete filling 

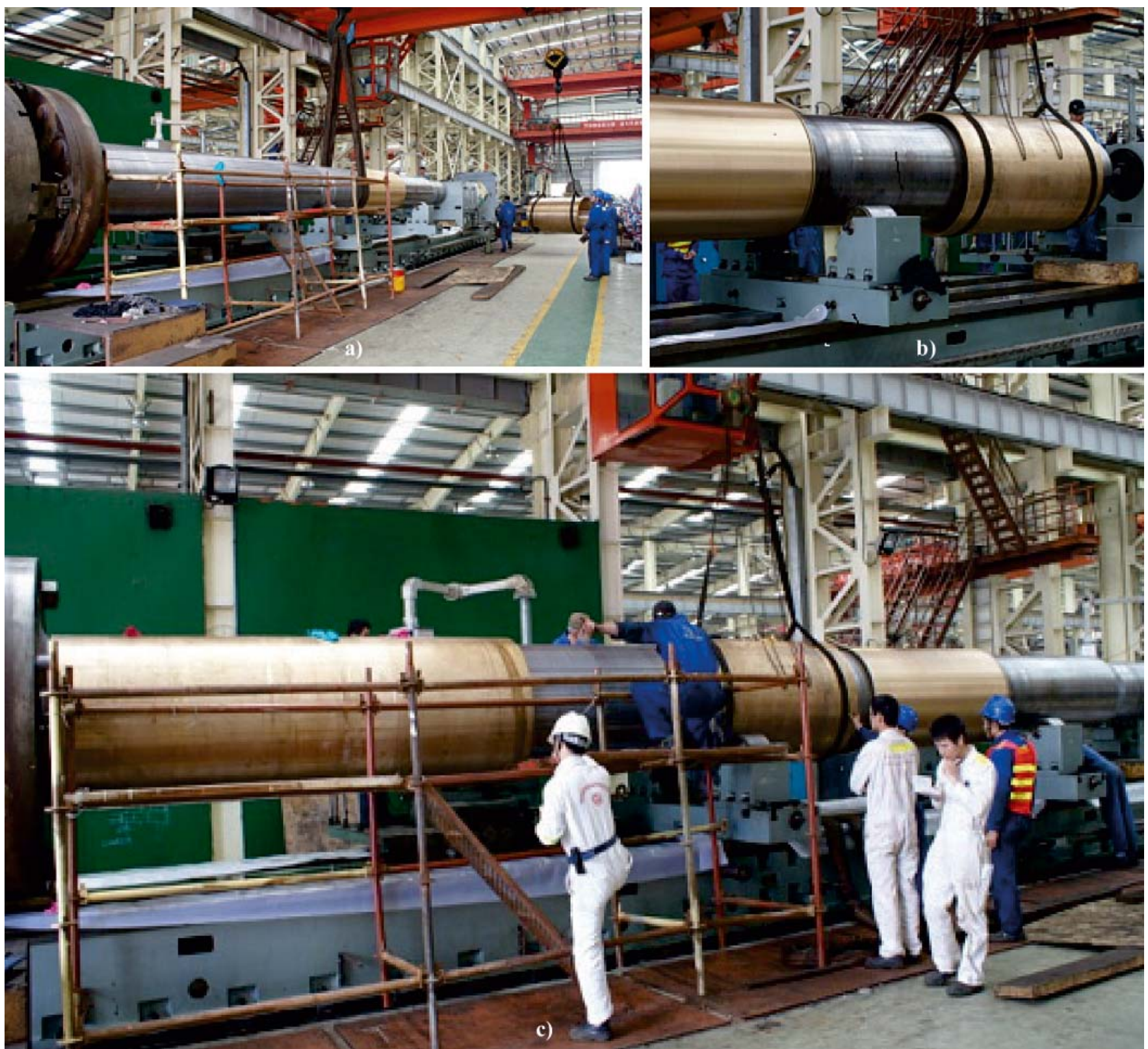

Fig. 6. Run of putting the particular sections of the bearing sleeve onto the shaft

the pouring space. This is necessary for supplementing void cavities resulting from a sealing foam elasticity, resin shrinkage during curing process, and other causes.

During the assembling work the ambient temperature in the workshop was $20 \div 24^{\circ} \mathrm{C}$. Before filling the system by the resin compound it was decided to heat it up to about $30^{\circ} \mathrm{C}$, that had to bring better and faster filling the pouring space. The system (Fig. 7a) was covered with a tarpaulin and heated up by blowing warm air for about 24 hours. To this end three small electric heaters were applied. At the instant of starting the pouring process the measured temperature of the sleeve was equal to $27^{\circ} \mathrm{C}$, and that of the poured resin compound to $30^{\circ} \mathrm{C}$. The resin compound was simultaneously poured through three holes: two extreme and one intermediate (Fig. 7a). The manner of pouring the resin compound is shown in Fig. $7 \mathrm{~b}$. The pouring proceeded continuously and uniformly.

The necessary amount of the resin compound was precisely calculated in advance. During pouring, were observed control points at the end seals and the joints of the sleeve, which served as additional venting. When the resin compound has been seen in the holes they were suitably sealed. The total time of pouring lasted 3 hours. After complete filling the pouring space the ingate and flow-off elements were monitored for next two hours and the resin compound was added to supplement void cavities and maintain an appropriate hydrostatic pressure. The total amount of the poured resin compound was 98.6 liters. After two hours the process of lowering the resin compound level in the ingate and flow-off elements, ceased. After next twelve hours the ingate and flow-off pipes as well as the adhesive tape seals on the joints of the sleeve, were removed. The holes in the bearing sleeve, left from the pouring pipes, were blanked off with threaded stoppers made of the same bronze material as that used for the sleeve itself. During the resin compound pouring and curing process no increase of the sleeve temperature was observed. The curing proceeded in the ambient temperature of $20 \div 24^{\circ} \mathrm{C}$ and lasted 36 hours. The resin compound hardness measured on especially cast specimens amounted to $42 \div 46^{\circ} \mathrm{B}$. The checking if the pouring space is fully filled was done by a simple „knocking” method, and control holes were drilled in dubious places indicated by a surveyor. No resin compound lacking zones 

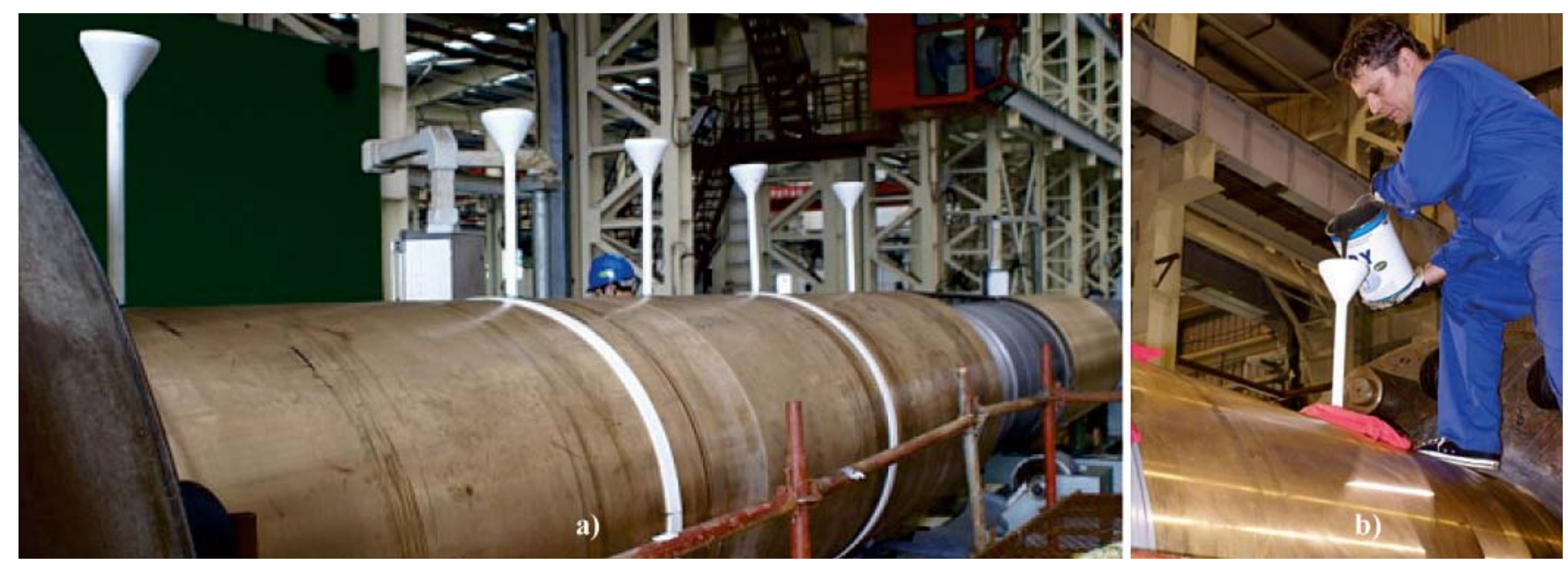

Fig. 7. a) the sleeve-shaft system prepared for pouring with resin compound, b) manner of pouring

were revealed. After ending the assembling work the sleeve surface were subjected to after-machining to remove the small surplus left.

\section{FINAL COMMENTS AND CONCLUSIONS}

- The presented novel design project of assembling the large bearing sleeve on the propulsion shaft of sea-going ship by using the special EPY epoxide resin compound, as well as the elaborated and applied technology of its realization, were successfully put in practice. The used solution passed an exam in practice. After over - a - year period of operation of the repaired ship a written confirmation stating correct performance of the sleeve assembled on the shaft, and the stern bearing, was received from the ship's operator. Until now, i.e. for three-year period of operation of the ship in question, no claim concerning this matter has been reported.

- The results of the work show one of many other possible in practice applications of the elaborated EPY resin compound to solving difficult and sophisticated assembling problems which happen in building and repairing processes of seagoing ships.

- Owing to elaboration and application of special polymer resin compounds, many difficult and complex problems dealing with design and technology of assembling as well as repair of many machines and devices, which earlier have produced many troubles for designers, manufacturers and users of such objects, have been solved successfully. In some cases such solutions as that discussed in this paper, are the only practically feasible in a given situation.

- Many advantages of the advanced assembling technology of machines and devices by using the resin compound resulted in that it has appeared widely applicable not only in building and repair of sea-going ships (where it has found its beginnings and became standard one), but also more and more often to assembling many different land-based objects. There are still many possible practical applications of resin compounds for achieving these way great technical, economical and operational profits both in shipbuilding and civil engineering. These authors have systematically conducted for many years R\&D work in the area in question in tightly connection with practical activity.

\section{Acknowledgement}

This publication has been elaborated and partially financed within the research project N N502 1949380 subsidized with the state Fund for Scientific Research by the Ministry for Science and Higher Education

\section{BIBLIOGRAPHY}

1. Grudziński K., Jaroszewicz W.: Seating of machines and devices on foundation chocks cast of EPY resin compound. Published by ZAPOL - Dmochowski \& Sobczyk Registered Partnership, Szczecin, 2002 (in Polish), 2004 (in English), 2006 (in Russian)

2. Piaseczny L.: Polymer technology in ship repair (in Polish ). Gdańskie Towarzystwo Naukowe (Gdańsk Scientific Society), Gdańsk, 2002

\section{CONTACT WITH THE AUTHORS}

Karol Grudziński, Prof.

Paweł Grudziński, Ph. D.

West Pomeranian University of Technology, Szczecin Faculty of Mechanical Engineering and Mechatronics Al. Piastów 19

70-310 Szczecin, POLAND e-mail: Karol.Grudzinski@zut.edu.pl

Wiesław Jaroszewicz, Ph. D.

Jędrzej Ratajczak, Ph. D.

Marine Service Jaroszewicz S.C., Szczecin 